\title{
$\beta$-Galactosidase mediated release characteristics of lornoxicam loaded guar gum microspheres: evaluation and product development
}

\author{
Abdesh Singh, Manish Kumar, Kamla Pathak* \\ Department of Pharmaceutics, Rajiv Academy for Pharmacy, Mathura, U.P, India \\ Received: Nov 22, 2015, Revised: Dec 20, 2015, Accepted: Dec 26, 2015
}

\begin{abstract}
The present investigation was aimed at developing a novel colon targeted system of lornoxicam based on the use of a combination of $\mathrm{pH}$ dependent system (to prevent the premature release of drug in the upper GIT) and enzymatically degradation system (to ensure the specificity of drug release in the colon). The drug loaded guar gum microspheres prepared by emulsification cross-linking method were assessed for the effect of guar gum concentration and the viscosity of external phase on the yield, particle size, entrapment efficiency and in vitro release. The in vitro performance of microspheres showed polymer concentration dependent sustained release and the release data best fitted Higuchi kinetics. Microscopic evaluation of the optimized formulation (M1) revealed spherical particles that comprised drug in amorphous state as deduced by DSC. DRS revealed zero interaction between drug and guar gum despite the processing steps. The optimized microspheres were formulated as colon targeted tablets by coating with Eudragit S 100 and its sequential analysis in gastrointestinal tract simulated media revealed complete protection against drug release in gastric and intestinal media. In the colon simulated medium (phosphate buffer, $\mathrm{pH} 6.8$ with $\beta$-galactosidase enzyme) the drug release was initiated and the tablet M1F3 manifested completed release $(97.85 \pm 0.48 \%)$ of the drug. The roentegenographic study in rabbits revealed maintenance of tablet integrity up to $7 \mathrm{~h}$ and thereafter on reaching the colonic junction the tablet size reduction was initiated due to enzymatic action in colon that was continued till $10^{\text {th }} \mathrm{h}$ providing proof of concept for colon targeting efficacy.
\end{abstract}

Keywords: Lornoxicam, microspheres, eudragit $\mathrm{S}$ coated tablet, $\beta$-galactosidase mediated release, roentegenography

\section{Introduction}

In the past few years various approaches have been reported for the colon targeting (covalent linkage of drug with a carrier, coating with polymers, microflora activated system and pressure controlled systems (1). The $\mathrm{pH}$ dependent polymer coating systems of colon targeting present the problem of site specificity of drug release in the colon and may produce premature drug release in the small intestine or no release of drug in colon (2). Similarly, 
in the time dependent systems the gastric emptying rate of small intestine and colon is varied due which premature drug release in the small intestine or delayed or no drug release in the colon (3). The microflora activated systems have the difficulty of controlling release of drug from the polysaccharide because of hydrophilic nature and hydrolysed by the colonic microflora (4) and pressure control systems requires special equipments, high amount of compression material (5). So to achieve optimal drug targeting to the colon, and to eliminate the disadvantages of coating with polymers, microbial degradation systems and pressure activated systems, a more advantageous and novel approach would be the use of a combination of $\mathrm{pH}$ dependent system (to prevent the premature release of drug in the upper GIT) and microbial degradation system (to ensure the specificity of drug release in the colon). Lornoxicam (chlortenoxicam), a nonsteroidal anti-inflammatory drug of the oxicam class, is available in oral and parenteral formulations. It is distinguished from established oxicams by a relatively short elimination halflife (3 to 5 hours), which may be advantageous from a tolerability standpoint. Lornoxicam has a tolerability profile characteristic of an NSAID, with gastrointestinal disturbances being the most common adverse events (6). A COX-2 inhibitor, it undergoes extensive and highly variable hepatic first pass metabolism following oral administration and has a bioavailability between $80-90 \%$ (7). The molecule has garnered considerable attention by the researchers for development of colon targeting drug delivery systems. Research reports on colon targeted matrix tablets of lornoxicam using tamarind seed polysaccharide has been reported by Manasa et al (8) and guar gum based matrix microspheres by Keraliya et al. (9). These reports primarily claim development and in vitro evaluation of either the matrix dosage form or the microspheres wherein the in vivo evaluation has not been detailed. Use of rat ceacal in dissolution media has potential to significantly interfere in the in vitro release testing. Hence the present project was aimed at developing a patient compliant dosage form (tablet) of lornoxicam loaded microspheres and the drug release evaluation was based on incorporation of colonic enzyme in the in vitro release test medium.

In the colon various metabolic reactions that are keys for the degradation of polysaccharides are mediated the colonic micro flora. Guar gum, a hydrocolloid polysaccharide widely used for the preparation of microspheres for colon targeting (10) was selected for the project. In order to ensure safe transit of the dosage form to the colon, coating of the delivery system was proposed. While coating of the multiparticulate systems has been reported by many researchers $(11,12)$ it is difficult to scale up. When a larger batch is to be coated chances of leaching of the drug from the microspheres into the organic solvent in which the polymer is dissolved may lead to decrease in the drug content of the microspheres (13). This problem can be overcome by making a suitable dosage form of the microspheres like tablet which can present the advantage of providing high reproducibility and industrial applicability because coating of tablet is easier than the microspheres and there is no chance of drug leaching 
in to the organic solvent. On tablet disintegration in colon, the microspheres will get dispersed into the lower part of GIT where the drug will be released due to action of colonic micro flora on the guar gum.

Based on these considerations, tabletted guar gum microspheres of lornoxicam were aimed for its colonic delivery wherein the tablet was coated with $\mathrm{pH}$ dependent polymer to specifically release the microspheres in colon and the integrity and performance characteristics were proven by roenteographic studies in rabbits.

\section{Matterials and methods}

\section{Materials}

Lornoxicam was received as a gift sample from Sun Pharma Pvt. Ltd, Ahmadabad, Gujarat, India. Guar gum was purchased from Sigma Aldrich, New Delhi; Eudragit S100 was provided by Evonik Degussa, Mumbai, India; Tween 80 and glutaraldehyde were procured from S.D. fine Chemicals Ltd, Mumbai, India; $\beta$-galactosidase was received from Sigma Aldrich New-Delhi India; dimethyl formamide was obtained from Rankem RFCL Ltd, New Delhi, India; all the ingredients were of analytical grade.

\section{Preparation of microspheres}

Drug loaded guar gum microspheres were prepared by slight modification of the emulsification cross-linking method (14). An aqueous dispersion of guar gum (50 $\mathrm{mL}$ ) containing $2 \% \mathrm{w} / \mathrm{v}$ of guar gum (an accurately weighed amount of guar gum dispersed in specified volume of cold water containing drug and allowed to swell for $4 \mathrm{~h}$ ) was poured in $75 \mathrm{~mL}$ of light/heavy liquid paraffin containing Span 80 $(3 \% \mathrm{w} / \mathrm{w})$ using a mechanical stirrer at $400 \mathrm{rpm}$. After complete mixing, $0.2 \mathrm{~mL}$ of concentrated $\mathrm{H}_{2} \mathrm{SO}_{4}$ and $1.5 \mathrm{~mL}$ glutaraldehyde were added drop wise to the dispersion at each hour of stirring, followed by stirring at a constant speed $700 \mathrm{rpm}$ for $4 \mathrm{~h}$ at $50{ }^{\circ} \mathrm{C}$. The microspheres formed were allowed to sediment for $2 \mathrm{~h}$ and the microspheres were collected by decantation of oil, and then washed with several fractions of isopropyl alcohol $(95 \% \mathrm{v} / \mathrm{v})$. The final preparation after filtration were dried at $50{ }^{\circ} \mathrm{C}$ and stored in dessicator. A total of six formulations were prepared (M1M6) by varying the external phase and the concentration of guar gum. The quantity of drug was kept constant in all the formulations. The key components and the formulation design are shown in Table 1. The microspheres were evaluated for percent yield, particle size and percent cumulative drug release (CDR) for $8 \mathrm{~h}$.

Table 1 Formulation composition of guar gum microspheres

\begin{tabular}{cccc}
\hline $\begin{array}{c}\text { Batch } \\
\text { code }\end{array}$ & $\begin{array}{c}\text { Lornoxicam } \\
\text { (mg) }\end{array}$ & $\begin{array}{c}\text { Guar } \\
\text { gum } \\
\text { (mg) }\end{array}$ & $\begin{array}{c}\text { External } \\
\text { phase }\end{array}$ \\
\hline M1 & 100 & 100 & LLP $^{\mathrm{a}}$ \\
M2 & 100 & 200 & LLP \\
M3 & 100 & 300 & LLP \\
M4 & 100 & 100 & HLP $^{\mathrm{b}}$ \\
M5 & 100 & 200 & HLP \\
\hline M6 & 100 & 300 & HLP \\
\hline
\end{tabular}

1- LLP : Light liquid paraffin ;

2- HLP : Heavy liquid paraffin 
Yield

The yield was calculated against the dried weight of drug and polymer using equation 1 :

Production Yield $=\frac{\text { Weight of microspheres }}{\text { Weight of drug }+ \text { Weight of Polymer }} \times 100$

\section{Particle size}

The microspheres were subjected to particle size distribution study using optical microscope. The eye piece ocular micrometer (Metzer Biomedical and Electronics, Mumbai, India) of microscope was calibrated using a standard stage micrometer (Metzer Biomedical and Electronics, Mumbai, India). The sample was mounted on a slide and placed on the mechanical stage. The mean particle size was calculated by measuring more than 200 particles to estimate true mean (15).

Drug content and loading efficiency The drug loaded guar gum microspheres were first crushed using a glass mortar pestle. Microspheres theoretically equivalent to $10 \mathrm{mg}$ of drug were weighed and extracted using $5 \mathrm{~mL}$ DMF. The resultant dispersion was vortexed for $10 \mathrm{~min}$, followed by centrifugation (2000 rpm for $15 \mathrm{~min}$ ) and the supernatant was analyzed spectrophometrically using UV absorption spectroscopy (Pharmspec 1700, Shimadzu, Kyoto, Japan) at 371 nm. The drug content and loading efficiency were calculated using following equations:

$\%$ Drug Content $=\frac{\text { Practical drug content }}{\text { Theortical drug contewnt }} \times 100$

(2)

Loading Efficiency $=\frac{\text { Drug loaded in microspheres }}{\text { Total weight of microspheres }} \times 100$

(3)

\section{Equilibrium swelling}

Weighed amount (100 mg) of microspheres was placed in phosphate buffer, $\mathrm{pH} 7.4$ and allowed to swell to a constant weight. The microspheres were removed at specific time interval and blotted with tissue paper, and changes in weight were then calculated from equation 4:

$$
\alpha=\frac{w f-w i}{w i}
$$

Where, $\alpha$ is the degree of swelling, $\mathrm{W}_{\mathrm{i}}$ is the initial weight of the microspheres and $\mathrm{W}_{\mathrm{f}}$ is the weight of the microspheres at equilibrium swelling in the medium.

\section{In vitro drug release}

Microspheres equivalent to $10 \mathrm{mg}$ of drug were subjected to in vitro drug release study. The study was performed in $900 \mathrm{~mL}$ of phosphate buffer, $\mathrm{pH} 6.8$ for $8 \mathrm{~h}$ using USP apparatus 1 (Basket type) with mesh size \#120 at $150 \mathrm{rpm}$ maintained at $37 \pm 0.5^{\circ} \mathrm{C}$. Aliquots were withdrawn periodically at hourly interval till $8 \mathrm{~h}$ and the sink conditions were maintained by adding equal amount of fresh release medium. The samples were analyzed spectrophotometrically at $371 \mathrm{~nm}$ and $\%$ cumulative drug release versus time plots were constructed.

Selection and evaluation of best formulation

The determinants of M1-M6 formulations were analyzed and best formulation was selected based on least particle size and maximum production yield and $\%$ cumulative drug release at 
$8^{\text {th }}$ hour. The selected formulation was evaluated for a series of pharmaceutical properties.

\section{Scanning electron microscopy (SEM)}

The photomicrographs of pure drug, blank microspheres, best formulation (M1) and surface of best formulation were obtained by scanning electron microscopy to assess the morphological features of the microspheres and its surface before and after drug release (Model LEO 435 VF, LEO electron microscopy limited, Cambridge, England). The samples were prepared by sprinkling the microspheres on a double adhesive tape adhered to aluminium stub. Particles were coated with thin gold layer by sputter coater unit. Coating was done for 5-6 min under an argon atmosphere in order to make them conductive. The surface morphology of both blank microspheres and lornoxicam loaded microspheres was also visualized. Micrographs were obtained at $100 \mathrm{X}$ to $2500 \mathrm{X}$ magnification with JEOL-5400, Tokyo, Japan.

\section{Differential scanning calorimetry (DSC)}

Thermal behavior of lornoxicam, guar gum and M1 was estimated by Differential scanning calorimeter Q10 V9.4 Build 287 (TA Instruments, New Castle, DE, USA). The instrument was equipped with an intracooler to assess the changes in chemical properties of powders. An indium standard was used to calibrate the temperature and enthalpy scale in the instrument. A continuous inert atmosphere is maintained by giving nitrogen at a flow rate of $60 \mathrm{~mL} / \mathrm{min}$. The samples were sealed using aluminium pans with heating rate of $10^{\circ} \mathrm{C} / \mathrm{min}$. Temperature range of $0-450{ }^{\circ} \mathrm{C}$ was also maintained.

\section{Diffuse reflectance spectroscopy}

To analyze the chemical interaction between the excipients and drug, diffuse reflectance spectroscopy analysis was performed. The samples of lornoxicam, guar gum, blank microspheres and drug loaded microspheres along with their physical mixtures diluted with $\mathrm{KBr}$ in the ratio 1:9 and placed in a sample cup mounted in the instrument. The resultant spectrographs were recorded in terms of transmittance mode (\% T) using FTIR spectrophotometer (Shimadzu FTIR-8400, Kyoto, Japan with DRS attachment) in the range of 400 and $4000 \mathrm{~cm}^{-1}$.

\section{Tabletting of optimized microspheres} (M1)

The optimized drug loaded formulation of microspheres was compressed into tablets using microcrystalline cellulose (Avicel® PH 301) and guar gum as diluents. PVP K30 (5\%w/v solution) was used as binder and aerosil as flow promoter. Composition of the tabletted microspheres (Batches F1-F6) is shown in Table 2. All the ingredients were mixed in the required amount and the tablets were compressed by direct compression technique using single station electrically operated tablet punching machine (Jindal Industries, Ambala, India).

\section{Physical characterization of tablets}

The tablets were evaluated for weight variation, thickness and hardness. In all, 10 tablets from each formulation were determined using an electronic balance (Sansui Electronics, Parwanoo, India) to 
Table 2 Evaluation parameters of lornoxicam loaded microspheres

\begin{tabular}{|c|c|c|c|c|c|c|c|c|c|c|}
\hline $\begin{array}{l}\text { Batch } \\
\text { Code }\end{array}$ & $\begin{array}{l}\text { Particle size } \\
\qquad(\mu \mathrm{m})\end{array}$ & $\begin{array}{l}\text { Yield } \\
(\%)\end{array}$ & $\begin{array}{c}\text { Drug content } \\
(\%)\end{array}$ & $\begin{array}{c}\text { Loading } \\
\text { efficiency } \\
(\%)\end{array}$ & $\begin{array}{c}\% \text { CDR }^{*} \text { at } \\
8^{\text {th }} \mathbf{h}\end{array}$ & $\begin{array}{c}\text { Degree } \\
\text { of } \\
\text { swelling }\end{array}$ & $\begin{array}{c}\text { Zero } \\
\text { order } \\
\left(\mathbf{r}^{2}\right)\end{array}$ & $\begin{array}{c}\text { First } \\
\text { order } \\
\left(\mathbf{r}^{2}\right)\end{array}$ & $\begin{array}{c}\text { Matri } \\
\mathbf{x} \\
\left(\mathbf{r}^{2}\right)\end{array}$ & $\begin{array}{c}\text { Peppas } \\
\left(\mathbf{r}^{2}\right)\end{array}$ \\
\hline M1 & $143.2 \pm 2.34$ & $57.50 \pm 0.36$ & $62.77 \pm 1.06$ & $49.46 \pm 0.45$ & $79.91 \pm 0.32$ & 0.40 & 0.909 & 0.932 & 0.999 & 0.538 \\
\hline M2 & $190.8 \pm 1.51$ & $62.50 \pm 0.76$ & $67.93 \pm 1.47$ & $32.52 \pm 0.65$ & $74.36 \pm 0.62$ & 0.50 & 0.884 & 0.841 & 0.978 & 0.963 \\
\hline M3 & $232.2 \pm 6.18$ & $65.17 \pm 0.54$ & $71.41 \pm 1.24$ & $23.21 \pm 0.32$ & $70.68 \pm 0.37$ & 0.60 & 0.936 & 0.790 & 0.980 & 0.862 \\
\hline M4 & $154.8 \pm 4.98$ & $56.21 \pm 0.81$ & $64.74 \pm 0.23$ & $46.43 \pm 0.94$ & $80.93 \pm 0.25$ & 0.50 & 0.901 & 0.822 & 0.9947 & 0.8211 \\
\hline M5 & $209.7 \pm 2.03$ & $60.92 \pm 0.12$ & $66.38 \pm 0.58$ & $30.39 \pm 0.75$ & $73.05 \pm 0.24$ & 0.70 & 0.8973 & 0.8963 & 0.9932 & 0.9912 \\
\hline M6 & $275.4 \pm 7.17$ & $64.68 \pm 0.54$ & $70.74 \pm 0.73$ & $23.61 \pm 0.64$ & $67.79 \pm 0.41$ & 0.90 & 0.9515 & 0.8807 & 0.9924 & 0.9810 \\
\hline
\end{tabular}

*CDR: Cumulative Drug Release

verify the uniformity of weight. The mean weight was expressed in $\mathrm{mg}$. For each formulation, the hardness of tablets was examined using a Pfizer type hardness tester to measure the crushing strength of the tablets. The mean hardness was calculated and expressed as $\mathrm{kg}$. The thickness of the tablets was measured using vernier caliper (Mituyoto, Japan). Ten tablets of each formulation were used and the mean thickness was expressed in $\mathrm{mm}$.

\section{Drug content}

The drug content determination was carried out by crushing tablets $(n=3)$ and powder equivalent to $10 \mathrm{mg}$ of drug was taken and extracted using $5 \mathrm{~mL}$ DMF. The solution was filtered, suitably diluted with phosphate buffer, $\mathrm{pH} \quad 6.8$ and analyzed spectrophotometerically at $371 \mathrm{~nm}$.

\section{Coating of tableted microspheres}

The coating of tabletted microspheres was done with Eudragit S100 by dip coating method. The tablets were dipped in the solution of Eudragit S100 and were air dried for 15, 30 and $60 \mathrm{~min}$ respectively after each coating followed by drying in Hot air oven (HICON, Grover Enterprises, New Delhi, India) at $50 \pm 0.5{ }^{\circ} \mathrm{C}$. To check the integrity of coating, the tablets were stirred in dissolution vessel of USP 1 apparatus sequentially in $900 \mathrm{ml}$ in $0.1 \mathrm{~N} \mathrm{HCl}$ buffer, $\mathrm{pH} 1.2$ for $2 \mathrm{~h}$ and in phosphate buffer, $\mathrm{pH} 7.4$ for next $6 \mathrm{~h}$.

In vitro drug release

In vitro drug release study was performed in USP drug release basket type apparatus. The study was conducted in $0.1 \mathrm{~N} \mathrm{HCl}$ buffer, $\mathrm{pH} 1.2$ for $2 \mathrm{~h}$, phosphate buffer, $\mathrm{pH} 7.4$ for $6 \mathrm{~h}$ and phosphate buffer, $\mathrm{pH} 6.8$ with $\beta$ galactosidase enzyme, $120 \mathrm{IU}$ for $12 \mathrm{~h}$ in a sequential manner. The test conditions were $900 \mathrm{~mL}$ of media stirred at $50 \mathrm{rpm}$ and temperature was maintained at $37 \pm 0.5^{\circ} \mathrm{C}$. Aliquots were withdrawn at predetermined intervals and sink condition was maintained by addition of equal quantity of fresh media. Each sample was then analyzed in triplicate at $371 \mathrm{~nm}$. On the basis of percent cumulative drug release profile the best tablet was selected and subjected to in vivo roengenography. 
In vivo roentengenography

In vivo roentegenography study was done to prove the concept of colon targeting of the developed formulation. According to the protocol no (IAEC/RAP/3964) approved by the institutional Animal Ethics Committee, Rajiv Academy for Pharmacy, Mathura, India, three New Zealand white rabbits, weighing 3-3.5 kg, were used for the study. For the study the guar gum microspheres prepared by partially replacing lornoxicam with radioopaque barium sulphate and these microspheres were used for the compression of tablets. The enteric coating of prepared tablets was done according to the optimized batch. All rabbits were placed on overnight fasting with free access of water under $12 \mathrm{~h}$ light/dark cycles. After an overnight fasting, tabletted microspheres were administered to rabbit with $10 \mathrm{~mL}$ of water. X- Ray images were periodically $(0-10 \mathrm{~h})$ taken to traces the movement and behaviour of the tabletted microspheres in the GIT. X Ray images were taken in prone position by using L\&T Vision 100 (Carm) X-Ray machine (Larsen \& Turbo Limited, Mumbai, India), at $64 \mathrm{mAs}$ and $63 \mathrm{kV}$ voltage.

\section{Results}

A total of six formulations (M1-M6) were developed by varying the concentration of guar gum and the external phase. The developed microspheres were evaluated for particle size, loading efficiency and in vitro drug release.

\section{Yield}

The yield of guar gum microspheres was found to be in the ranged between $57.50 \pm 0.36 \%$ and $65.17 \pm 0.54 \%$ (Table 2). For a given type of external phase and constant amount of the drug, an increase in the guar gum concentration led to an increase in the yield the concentration of guar gum.

\section{Particle size}

The particle size of prepared microspheres was found in the range of $143.2 \pm 2.34$ to $275.4 \pm 7.17 \mu \mathrm{m}$ (Table 2 ). It was worth mentioning that the particle size of the microspheres was directly proportional to the polymer concentration.

\section{Drug content and loading efficiency}

The drug content ranged between 62.77 \pm 1.06 and $71.41 \pm 1.24 \%$. An increase in concentration of gaur gum resulted in increase in the drug content while an inverse relation was observed between the concentration of guar gum and loading efficiency (Table 2). At a given constant drug amount, on increasing the concentration of guar gum more amount of polymer was available for encapsulation of drug.

\section{Equilibrium swelling}

Swelling ability is a parameter that indicates quick availability of drug solution for diffusion. The swelling index was found to be in the range of 0.40 to 0.90 (Table 2).

\section{In vitro drug release}

The percent cumulative drug release in phosphate buffer, $\mathrm{pH} 6.8$ was found to be in range $70.68 \pm 0.37 \%$ (M3) to $80.93 \pm 0.25 \%$ (M4) suggesting the ability of microspheres to release most of its entrapped drug (Table 2). The in vitro release of drug was characterized by initial fast release for $1.5 \mathrm{~h}$ followed by a sustained release till next $7 \mathrm{~h}$ (Fig. 1). In order to elucidate the release mechanism, the in vitro release data was 


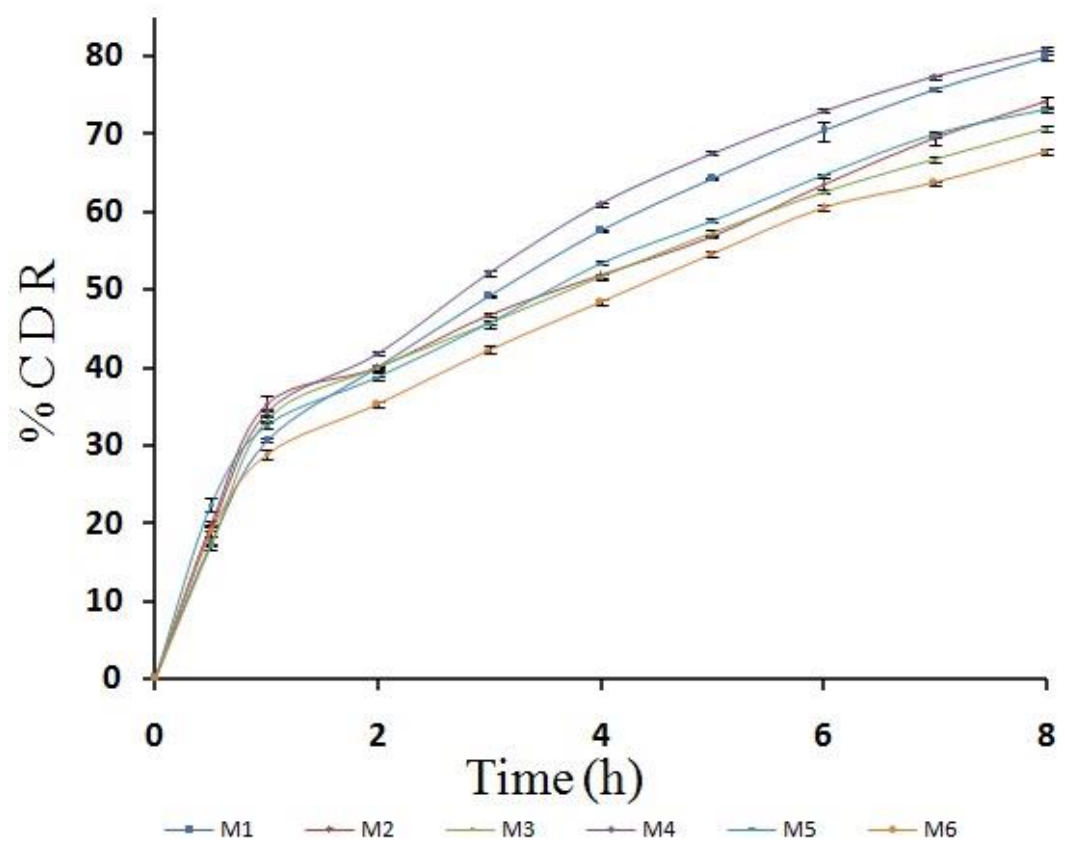

Figure 1 Comparative in vitro drug release profiles of lornoxicam loaded microspheres in phosphate buffer, 6.8 for $8 \mathrm{~h}$ at $37 \pm 0.5^{\circ} \mathrm{C}$.

subjected to model fitting and the $\mathrm{r}^{2}$ values (0.9780-0.9992) indicated that data best fitted matrix type release (Table 2). The results are consistent with widely published results on the matrix type release mechanism for microspheres.

\section{Selection of optimized microspheres}

On the basis of least particle size, highest drug loading, and high cumulative drug release M1 formulation was selected as the best formulation. Furthermore, in order to develop it as a tablet its powder properties were determined.

\section{Scanning electron microscopy}

Pure lornoxicam was rhombic shaped crystals (Fig. 2a) whereas the blank microspheres were discrete and spherical (2c). The enlarged view of drug loaded microspheres (2d) at 500X depicted spherical particles apparently smooth surfaced. However the magnified view of drug loaded microspheres (2b) shows polymeric folds, depressions and pitted surface probably an effect of processing variables.

Differential Scanning Calorimetry

DSC analysis of pure drug, guar gum, physical mixture and drug loaded microspheres was carried out and the results depict the thermal changes of interaction during the preparation of microspheres. A sharp exothermic peak of pure lornoxicam was recorded at $219.09{ }^{\circ} \mathrm{C}$ (Fig. 3a) corresponding to its melting point. The thermogram of gaur gum showed a broad endothermic peak (3b) at 106.25 ${ }^{\circ} \mathrm{C}$. In their physical mixture, the peaks of lornoxicam and guar gum were clearly recorded with insignificant influence on each other 


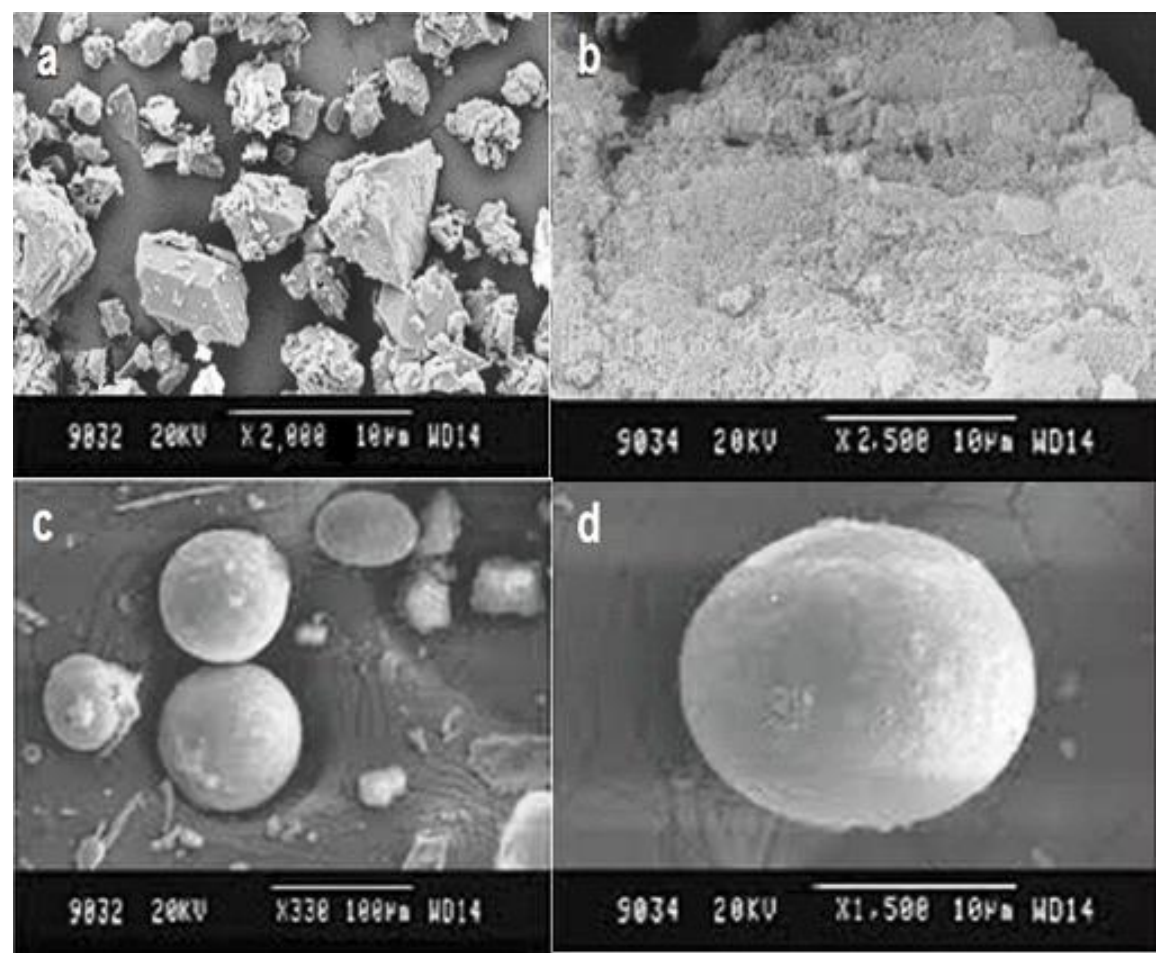

Figure 2 Scanning electron micrographs (a) pure lornoxicam, (b) surface of intact microspheres, (c) drug loaded microspheres, and (d) blank microspheres

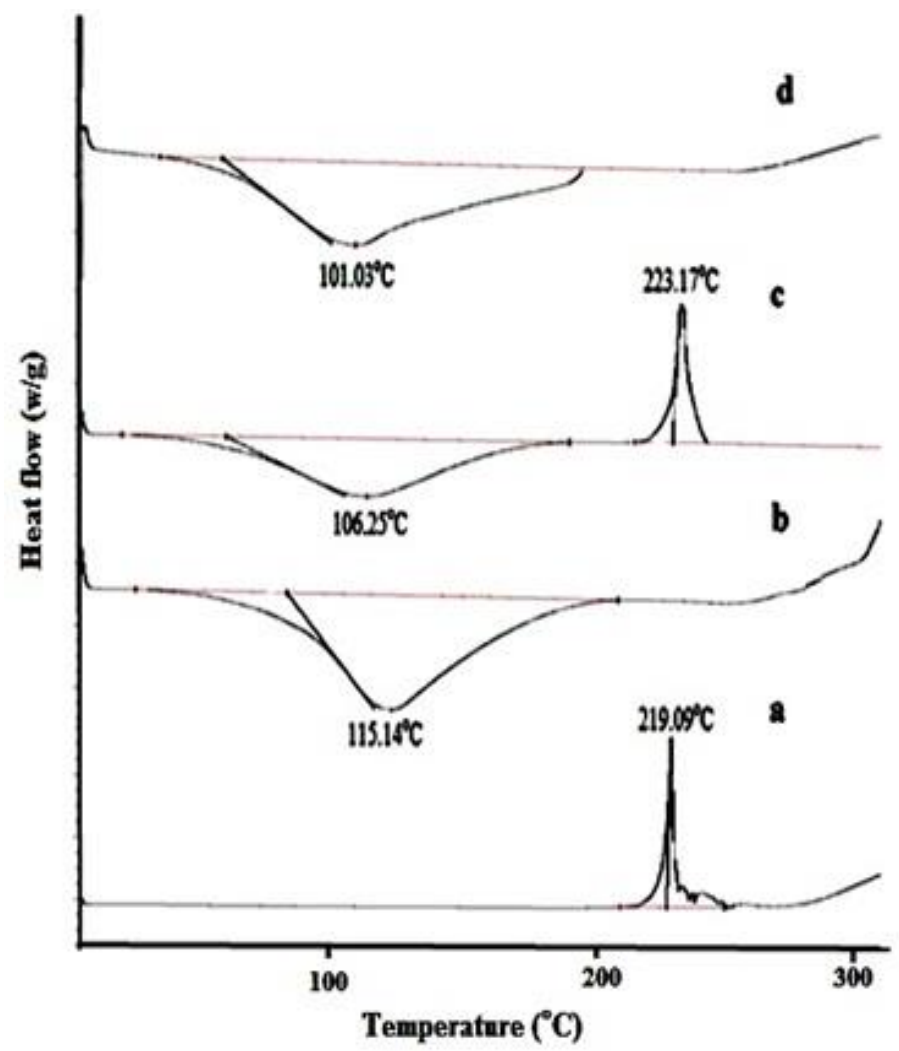

Figure 3 Differential scanning thermograms of (a) pure lornoxicam, (b) guar gum, (c) physical mixture, and (d) drug loaded microspheres. 
(3c). The peaks corresponded to 223.17 ${ }^{\circ} \mathrm{C}$ and $106.25^{\circ} \mathrm{C}$ respectively.

Diffuse reflectance spectroscopy (DRS) The blank microspheres and the drug loaded microspheres along with appropriate reference samples were subjected to infrared radiation to assess the interaction between the drug and polymer in microspheres. Lornoxicam showed the characteristics peaks (Fig. 4a) of $\mathrm{N}$ $\mathrm{H}$ bending $\left(1637.45 \mathrm{~cm}^{-1}\right)$, free $\mathrm{OH}$ $\left(3650.82 \mathrm{~cm}^{-1}\right), \mathrm{C}-\mathrm{Cl} \quad\left(626.82 \mathrm{~cm}^{-1}\right)$, $\mathrm{S}=\mathrm{O}$ asymmetric $\left(1332.72 \mathrm{~cm}^{-1}\right)$ and $\mathrm{C}-\mathrm{N}$ aromatic $\left(1238.21 \mathrm{~cm}^{-1}\right)$. The DRS spectrum of guar gum (Fig. 4B) demonstrated a characteristic peak at $3550 \mathrm{~cm}^{-1}$ for $-\mathrm{OH}$ stretching vibration and water involved in hydrogen bonding, whilst the peak at $1151 \mathrm{~cm}^{-1}$ was due to the CO bond.
The peak observed in the spectrum between 800 and $1200 \mathrm{~cm}^{-1}$ demonstrated highly coupled C-C$\mathrm{O}$, C-O-H and $\mathrm{C}-\mathrm{O}-\mathrm{C}$ stretching modes of polymer backbone. The DRS spectrum of the physical mixture of lornoxicam and guar gum was an additive spectrum of both due to the intermixing of the peaks. The blank microspheres showed characteristic peaks of guar gum however, the peak at $3550 \mathrm{~cm}^{-1}$ was subdued probably due to cross linked matrix. The peaks related to the drug were not present in the blank microspheres. On the other hand the drug related peaks were clearly identifiable in the drug loaded microspheres (M1) though the intensity of the peaks were less than those observed with pure drug but were of same intensity as that of the physical mixture.

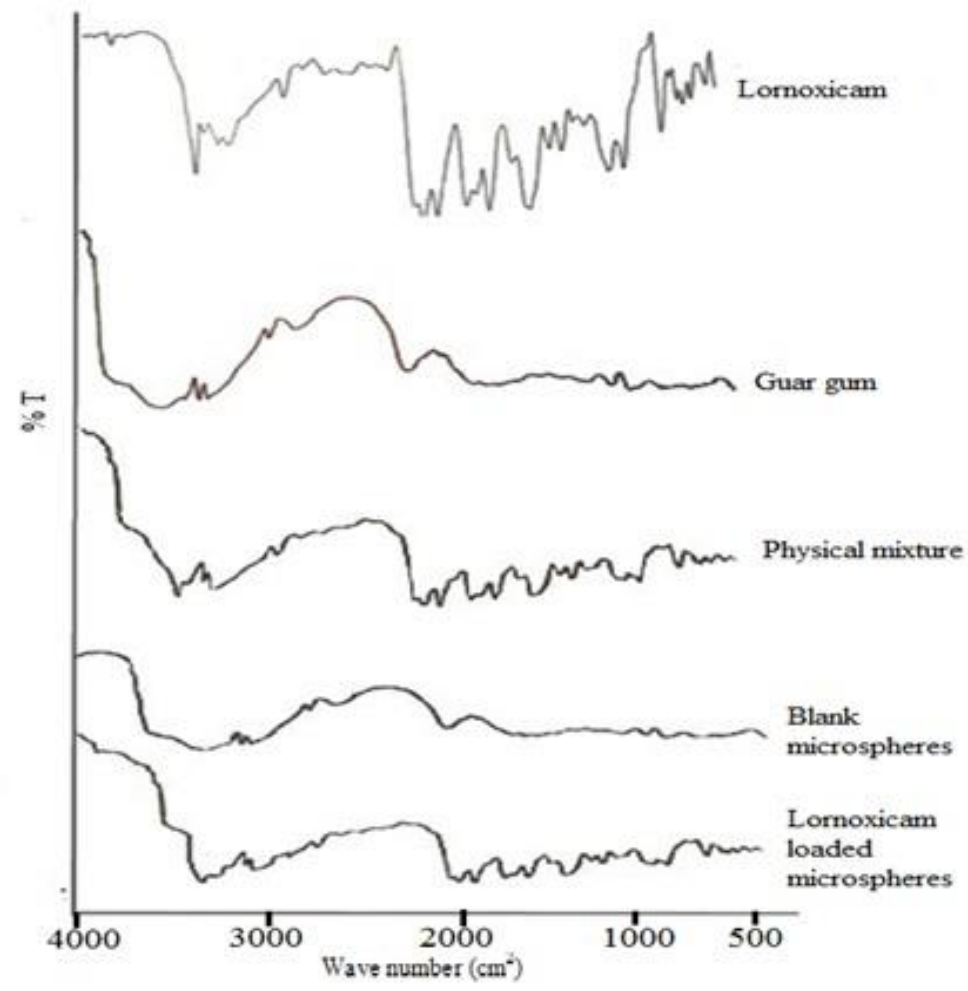

Figure 4 Diffuse Reflectance spectra of lornoxicam, guar gum, physical mixture, blank microspheres and drug loaded microspheres. 
Tabletted microspheres

The optimized formulation of lornoxicam loaded guar gum microspheres was tabletted using guar gum and microcrystalline cellulose as two separate diluents (Table 3). The tabletted microspheres were subjected to various tablet evaluation parameters and the results of the tests are given in table 4.

Optimization of coating integrity

The formulation M1F3 was subjected to Eudragit $\mathrm{S}$ coating and results are given in table 5 .

The formulation did not retain its intactness $0.1 \mathrm{~N} \mathrm{HCl}$ buffer, $\mathrm{pH} 1.2$ for $2 \mathrm{~h}$ when the number of coat was 1 and the drying time was $15 \mathrm{~min}$.
But when the number of coats increased to 2 and drying time was $15 \mathrm{~min}$ the formulation remained intact in $0.1 \mathrm{~N} \mathrm{HCl}$ buffer, $\mathrm{pH} 1.2$ for $2 \mathrm{~h}$ but not in phosphate buffer, $\mathrm{pH} 7.4$ (Table 5). Further on increasing the number of coats and drying time it was found that with 3 coats and 60 min drying time the coating integrity

was maintained in $\mathrm{HCl}$ buffer, $\mathrm{pH} 1.2$ for $2 \mathrm{~h}$ and in phosphate buffer, $\mathrm{pH} 7.4$ for $6 \mathrm{~h}$.

Thus these were selected as optimized coating conditions and all the formulations were dip coated with Eudragit S100 maintaining the three coats with a drying time of 60 min.

Table 3 Formulation composition of colon targeted lornoxicam microspheres (equivalent to $10 \mathrm{mg}$ drug) loaded tablets.

\begin{tabular}{ccccccc}
\hline $\begin{array}{c}\text { Ingredient } \\
(\mathbf{m g})\end{array}$ & M1F1 & M1F2 & M1F3 & M1F4 & M1F5 & M1F6 \\
\hline PVP K 30 & 10 & 15 & 20 & 10 & 15 & 20 \\
Aerosil & 2 & 2 & 2 & 2 & 2 & 2 \\
$\begin{array}{c}\text { Diluent } \\
\text { (q.s. 100 mg) }\end{array}$ & GG & GG & GG & MCC & MCC & MCC \\
\hline
\end{tabular}

Table 4 Characterization of colon targeted lornoxicam microspheres loaded tablets

\begin{tabular}{cccccc}
\hline $\begin{array}{c}\text { Formulation } \\
\text { code }\end{array}$ & $\begin{array}{c}\text { Uniformity of } \\
\text { weight } \\
\text { mg } \pm \text { S.D }\end{array}$ & $\begin{array}{c}\text { Thickness } \\
\mathbf{m m} \pm \mathbf{S D}\end{array}$ & $\begin{array}{c}\text { Friability } \\
(\mathbf{\%})\end{array}$ & $\begin{array}{c}\text { Hardness } \\
\left(\mathbf{k g} / \mathbf{c m}^{2} \pm \mathbf{S . D}\right)\end{array}$ & Drug content \\
\hline M1F1 & $101.0 \pm 7.25$ & $2.04 \pm 0.05$ & 0.92 & $3.44 \pm 0.30$ & $95.42 \pm 0.21$ \\
\hline M1F2 & $99.5 \pm 6.95$ & $2.04 \pm 0.06$ & 0.80 & $3.75 \pm 0.42$ & $94.56 \pm 0.34$ \\
M1F3 & $100.5 \pm 3.94$ & $2.01 \pm 0.00$ & 0.71 & $4.70 \pm 0.50$ & $94.71 \pm 0.46$ \\
\hline M1F4 & $98.5 \pm 5.87$ & $2.09 \pm 0.01$ & 0.85 & $3.60 \pm 0.28$ & $95.54 \pm 0.55$ \\
\hline M1F5 & $98.5 \pm 6.40$ & $2.11 \pm 0.01$ & 0.70 & $3.95 \pm 0.36$ & $96.65 \pm 0.22$ \\
\hline M1F6 & $102.0 \pm 6.40$ & $2.03 \pm 0.04$ & 0.54 & $4.30 \pm 0.31$ & $96.34 \pm 0.45$ \\
\hline
\end{tabular}


Table 5 Optimization of coating of tableted microspheres

\begin{tabular}{cccc}
\hline $\begin{array}{c}\text { Number } \\
\text { of } \\
\text { coating }\end{array}$ & $\begin{array}{c}\text { Drying time after each } \\
\text { coating } \\
\text { (min) }\end{array}$ & \multicolumn{2}{c}{ Coating integrity } \\
\cline { 2 - 4 } & 15 & $\begin{array}{c}\mathbf{0 . 1} \mathbf{~ N ~ H C l ~ b u f f e r , ~ p H ~ 1 . 2 ~} \\
\text { for 2h }\end{array}$ & $\begin{array}{c}\text { Phosphate buffer, } \\
\text { pH 7.4 for 6h }\end{array}$ \\
\hline 1 & 30 & - & - \\
& 60 & - & - \\
\hline 2 & 15 & + & - \\
\hline 30 & 60 & + & - \\
& 15 & + & - \\
\hline 30 & + & - \\
& 60 & + & - \\
\hline
\end{tabular}

In vitro drug release

The in vitro drug release profiles of coated tabletted microspheres (Fig. 5) showed no drug release in $\mathrm{HCl}$ buffer, $\mathrm{pH} 1.2$ for $2 \mathrm{~h}$ and in $<20 \%$ release in phosphate buffer, $\mathrm{pH} 7.4$ for another $6 \mathrm{~h}$ because of the coating. Poor release of lornoxicam can be attributed to the Eudragit S100 coat in the all the formulations.

\section{In vivo roentgenography}

For the proof of concept of colon targeting, the roentegenographic study was performed in rabbits. The enteric coated tabletted microspheres were found to be intact in stomach 2 to $4 \mathrm{~h}$ ( Fig.6a and $b$ respectively) which clearly indicates that the enteric coating of eudragit S100 was able to protect the release of microspheres in the gastric environment.

\section{DISCUSSION}

\section{Formulation considerations}

Several methods are reported for the development of microspheres, but the multiparticulate carriers of natural polymers especially those of protein and carbohydrates are best prepared by single emulsion technique. The natural polymer guar gum was dispersed in aqueous media followed by dispersion in liquid paraffin. In the second step cross- linking of dispersed globule was carried out. The cross linking can be achieved by heat or by using chemical cross linkers like glutaraldehyde, formaldehyde and di acid chloride (16). Based on these considerations, the microspheres were designed using guar gum as a polymer of choice as it is abundantly available and is obtained naturally from Cyamopsis tetragonolobous. Family: 


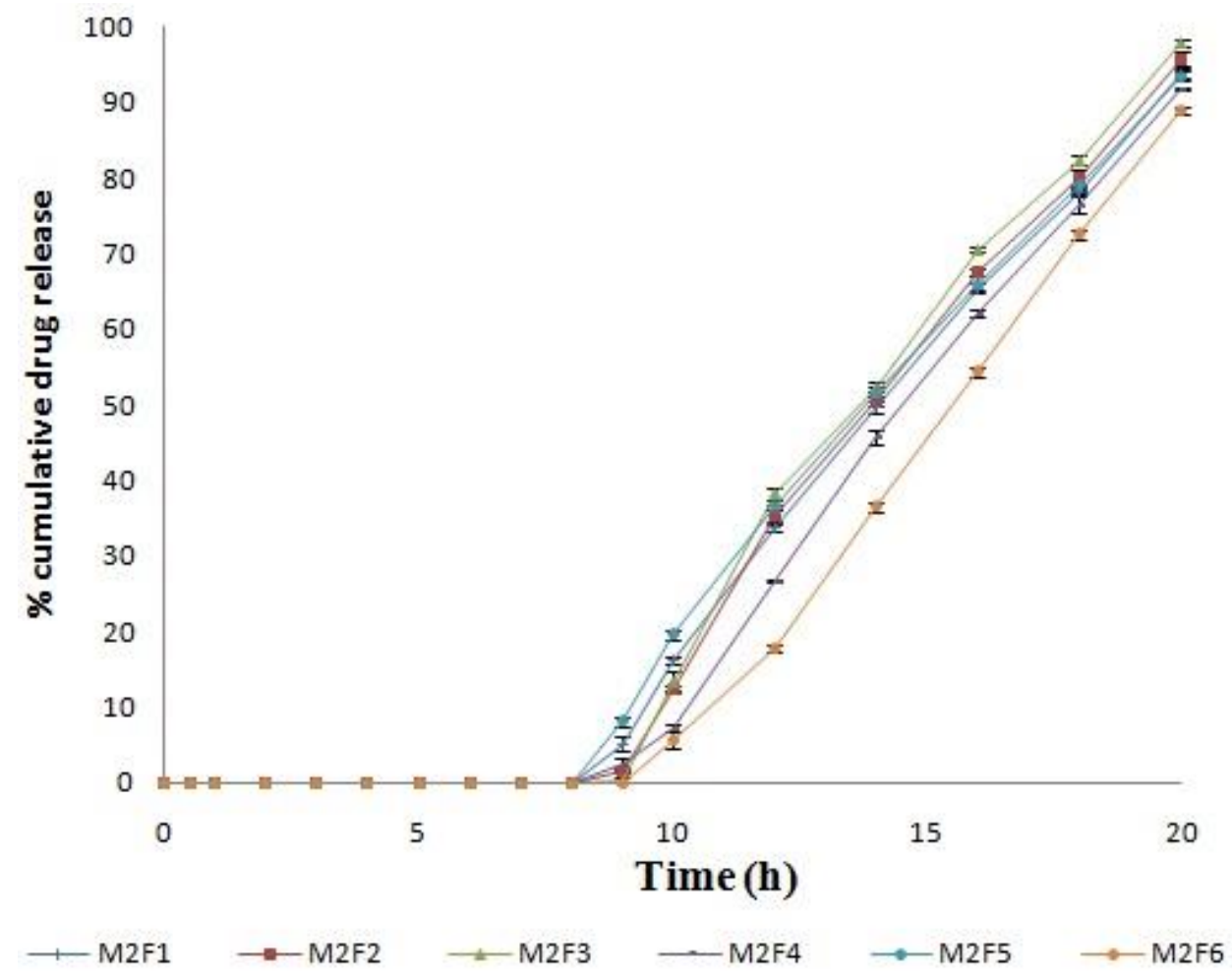

Figure 5 In vitro drug release profiles of tabletted microspheres, sequentially in $0.1 \mathrm{~N} \mathrm{HCl}$ buffer, $\mathrm{pH}$ 1.2 for $2 \mathrm{~h}$, phosphate buffer, $\mathrm{pH} 7.4$ for $6 \mathrm{~h}$ and phosphate buffer, $\mathrm{pH} 6.8$ with $\beta$-galactosidase till $12 \mathrm{~h}$ at $37 \pm 0.5^{\circ} \mathrm{C}$ using basket apparatus.

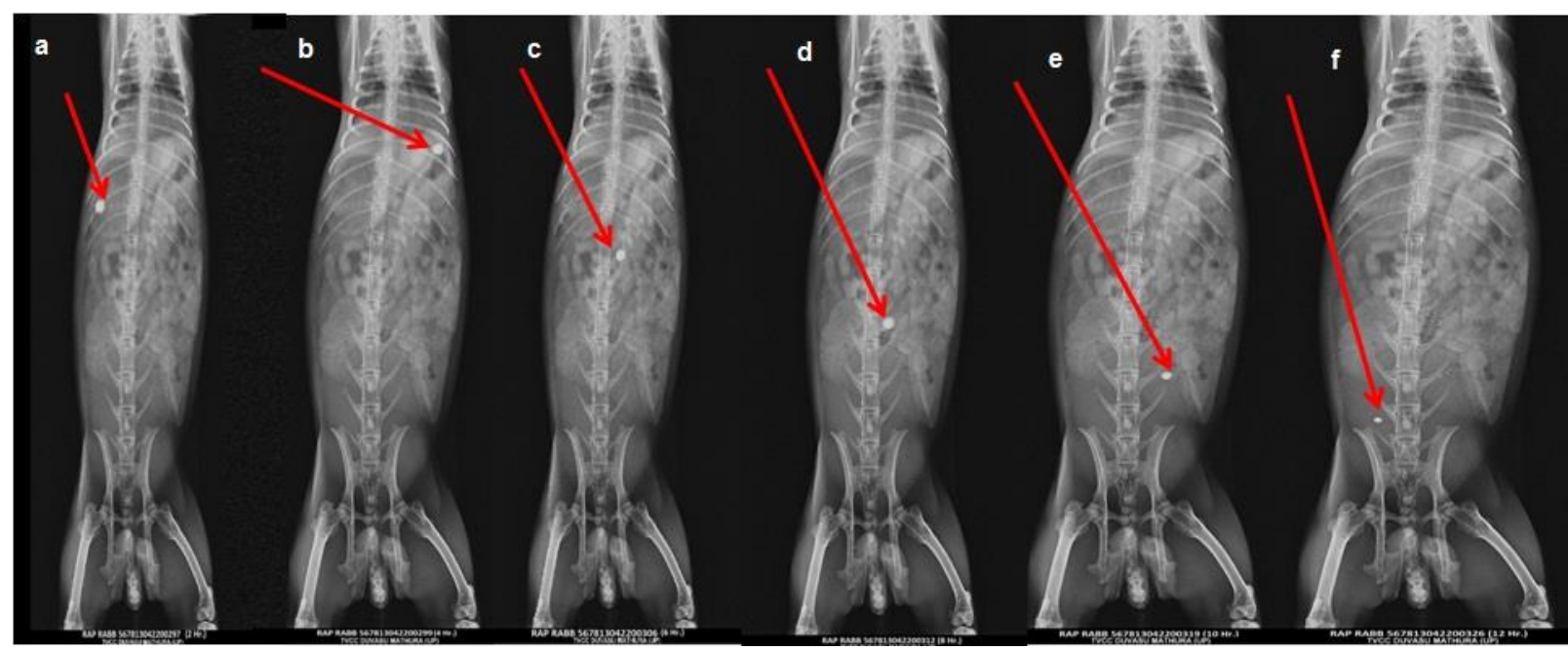

Figure 6 In vivo roentegenographic study of Eudragit $\mathrm{S}$ coated tabletted microspheres ( a) after 2 h of administration in stomach, b) at 4th $\mathrm{h}$ in stomach, c) after $6 \mathrm{~h}$ in small intestine, d) at 7 th $\mathrm{h}$ in small intestine, e) at 8 th $\mathrm{h}$ at the ileocaecal junction, and (f) At 10 th $\mathrm{h}$ in colon. 
Leguminosae). Guar gum has been extensively employed for colonic delivery (17), as on exposure to gastrointestinal fluid; it hydrates to form a viscous gel layer that slows down seeping in of the physiological fluid towards the core. This makes it efficient enough to prevent the release of drug in physiological environment of the stomach and the small intestine and thereby releasing the drug in colon (18). For hardening the microspheres, glutaraldehyde was used as cross linking agent which causes cross linking by reacting with hydroxyl group of galactose and mannose unit of guar gum. The effect can be explained as: at lower concentration of guar gum less viscous dispersion is produced which gets easily and rapidly mixed with the oily phases due to which the drug was precipitated and less droplets are formed (19).

As the concentration of guar gum increased, the particle size also increased. An increase in guar gum concentration increased and the polymer dispersion became thicker due to enhancement in the viscosity. Consequently larger droplets were formed and the particle size was increased. Additionally, as the polymer concentration increased, more amount of polymer was present for the encapsulation and this led to enhancement in particle size. The results are similar to those reported by $\mathrm{Wu}$ et al (20) on chitosan microspheres as well as to our earlier report on piroxicam microspheres (19). The effect of the type of the external phase on particles was evident by larger sized particles obtained when heavy liquid paraffin was used in comparison to light liquid paraffin; but the effect was insignificant.
As the drug: polymer ratio increased the polymer concentration in organic phase increased the diffusional resistance to the drug molecules from organic phase to aqueous phase, thus more drug was entrapped in the polymeric dispersion. On the other hand the results of decrease in loading efficiency on increasing guar gum are consistent with the reports of Rahman et al. (21). The decrease in loading efficiency can be attributed to cross linking density of guar gum. More the guar gum, more is cross linking density that resulted in production of rigid microspheres, thereby reducing the free volume spaces within the polymer matrix and hence a reduction loading efficiency (22). Furthermore, the swelling index was directly proportional to polymer concentration; as the polymer concentration increased swelling index increased; as also observed by Yadav et al. (23) in their report on biodegradable starch microspheres.

In vitro release of the drug from the microspheres showed biphasic release pattern which is characteristic of matrix diffusion kinetics. The constant release of the drug in sustained manner in later phase was a result of the diffusion of the drug from the matrix of microspheres (24). The release of drug from microspheres is reported to be dependent on the swelling property of polymer. More the swelling, lower the release. The release profile of guar gum microspheres in phosphate buffer, $\mathrm{pH}$ 6.8 for $8 \mathrm{~h}$ clearly indicates that guar gum slowed down the release of lornoxicam from the microspheres. It was observed that as the drug: polymer ratio varied from 1:1 through 1:3, the rate of drug release decreased (Fig. 1). On increasing the guar gum concentration, a decrease in the release 
rate was observed as a result of the increase in thickness of matrix, thereby increasing the path length that the drug passed through the surface of the microspheres (25). On the basis of least particle size, highest drug loading, and high cumulative drug release M1 formulation was selected as the best formulation.

The formulation was visualized by SEM and characterized by DSC and DRS. Spherical particles with apparently no crystalline drug deposits could be seen on the surface indicating molecular dispersion of the drug in the polymeric matrix. The physical state of drug in the microspheres was established by DSC. In the DSC thermogram of drug loaded microspheres the peak of lornoxicam did not appear (3d) probably due to solubilization of drug in the polymer / its molecular dispersion in the crosslinked polymeric matrix. However, the peak corresponding to guar gum was recorded at $101.03{ }^{\circ} \mathrm{C}$, a slight shift from $106.25{ }^{\circ} \mathrm{C}$ probably due to its cross-linked structure (26,27). Furthermore, the DRS spectroscopy clearly indicated no chemical interaction between lornoxicam and guar gum.

The optimized formulation (M1) was tabletted using guar gum and microcrystalline cellulose as two separate diluents. The tabletted microspheres were subjected to a series of tablet evaluation parameters. The tablet tooling resulted in nearly uniformly thick and weighted tablets the hardness varied with the increase in binder strength irrespective of the type of diluents. Thus M1 F3 showed maximum hardness followed by M1F6 and correspondingly friability was less was the former. The difference in the values was statistically insignificant.
The robust formulation M1F3 was selected for the purpose of optimization of coating for the development of colon targeted tablets. The tablet(s) was dip coated with Eudragit S100 and the optimized coating conditions were identified as three coats with a drying time of $60 \mathrm{~min}$.

For efficient colon targeting, the tablet must not disintegrate and matrix must remain intact during its passage through stomach and small intestine. Thus, to predict the fate of the tablet in stomach and small intestine, the coated tablets were subjected to in vitro drug release to find out the best formulation. Eudragit S100 is reported to solubilize at $\mathrm{pH} \geq 7$ (17) and the coat level of $10 \%$ $\mathrm{w} / \mathrm{v}$ proved to be effective in sealing the release of drug from the matrix tablets. It is therefore predictable that once the tablet reaches the small intestine, Eudragit S100 will slowly and continuously dissolve over time, leaving the tablet matrix exposed to the release medium. To precisely delineate the release behavior of these formulations during their transit from intestine to colon, $120 \mathrm{IU} / 900 \mathrm{ml}$ of $\beta$ galactosidase enzyme was included in phosphate buffer pH 6.8 to mimic the colonic environment. Enzymes are preferred to simulate the colonic conditions as simulation of colonic environment by addition of caecal content of rat or guinea pig, leads to hindrance in drug analysis due to turbidity of release medium. Furthermore, accurate measurement of drug release is not possible due to partial/complete adsorption of drug on the suspended caecal matter. Recently, the use of enzymatic release media containing pectinase and invertase has been reported by our research group to precisely assess the release behavior of 
colon targeted formulations. $(28,29)$ On changing the release media to phosphate buffer, pH 6.8 with $\beta$-galactosidase enzyme, the drug release was initiated. The tablet comprising guar gum (M1F1-M1F3) as the diluent manifested higher release $(93.81 \pm 0.73$ to $97.85 \pm 0.48 \%)$ due to the degradation of guar gum by $\beta$-galactosidase as compared to tablets made of MCC (M1F4-M1F6) as the diluent $(85.33 \pm 0.73$ $-88.96 \pm 0.46 \%$ ). The result of the study revealed that within in $20 \mathrm{~h}$ the tabletted microspheres released most of the drug content. The formulation M1F3 showed maximum CDR of $97.85 \pm 0.48 \%$ due to least amount of guar gum and hence rapid degradation by the enzyme $\beta$-galactosidase. Thus M1 F3 formulation was selected as the best tabletted microspheres and used for in vivo roentegenographic study.

No change was observed in the integrity of the tablet after $6 \mathrm{~h}$ in small intestine (6c) and remained intact up to $7 \mathrm{~h}(6 \mathrm{~d})$. After 8 $\mathrm{h}$ of administration the formulation reached to the colonic junction and tablet was apparently smaller in size as compared to original size of tablet which means that enteric coating of tableted microspheres started to dissolve (6e). Finally at the 10th hour of the administration the tablet was further reduced in size (6f) due to the degradation of guar gum by $\beta$-galactosidase and because of this the drug release is anticipated in the colon.

\section{References}

1. Patel MM, Amin AF. Process, optimization and characterization of mebeverine hydrochloride loaded guar gum microspheres for irritable bowel syndrome. Carbohydrate Polymer 2011;86:536-45.

2. Ashford M, Fell J., Attwood, D., Sharma, H. and Wopdhead, PJ. An in vitro investigation onto the suitability of $\mathrm{pH}$ dependent polymers for colonic targeting. J Pharm Sci 1993;95:193-9.

\section{Conclusion}

A simple, industrially viable colon targeted, guar gum based tablets of lornoxicam, coated with Eudragit S100 was successfully designed for the treatment of colonic disorders. Eudragit S100 was found to be capable enough to prevent the drug from being released in stomach and small intestine. And thus, tablet intactness was checked by in vivo roentgenographic studies thereby providing the proof of concept. The designed conceptual formulation revealed the ability of guar gum as a potential carrier for colon targeted system of lornoxicam that may be clinically useful once the intricacies are resolved.

\section{Acknowledgments}

The authors are highly thankful to the Dean, Pandit Deen Dayal Upadhaya Pashu Chikitsa Vigyan, Mathura, Uttar Pradesh, India for their assistance in performing the in vivo roentgenography study.

\section{Conflict of Interest}

The authors declared no conflict of interest.
3. Odze R. Diagnostic problems and advances in inflammatory bowel disease. Mod Pathol 2003;16:347-58.

4. Lichtenstein GR, Sbreu, MT, Cohen R, Tremaine W. American gastroenterological association institute technical review on corticosteroids, immunomodulators, and infliximab in inflammatory bowel disease. Gastroenterology 2006;130:940-87.

5. Krishnainh, Y SR, Satyanarayan S, Ramaprasad Y V, Narasimha RS. 
Evaluation of guar-gum as compression coat for drug targeting to colon. Int J Pharm 1998; 171:137-46.

6. Balfour JA, Fitton A, Barradell LB, Lornoxicam. A review of its pharmacology and therapeutic potential in the management of painful and inflammatory conditions. Drugs 1996;51:639-657.

7. McCartney SA, Mitchell JA, Fairclough PD, Farthing MJG, Warner TD. Selective COX-2 inhibitors and human inflammatory bowel disease. Ail Pharmacol Ther 1999;13:1115-7.

8. Manasa B, Krishnan SK, Ahmed MG, Nagesh DR, Ramesh B. Formulation and in-vitro evaluation of colon targeted matrix tablets of lornoxicam, Int J Pharm Chem Sci 2013;2:25965 .

9. Keraliya RA, Shah VH. Formulation of colon targeted guar gum based matrix microsphere containing lornoxicam for effective treatment of ulcerative colitis. Int Res J Pharm Sci 2014;05:4-9.

10. Goldstein AM, Alter EN, Seaman JK. Guar gum In Whistler R. L. (Ed.), Industrial gums, Polysaccharides and their derivatives, New York, Academic Press, New York, 1973.

11. Chaurasia MK, Jain NK, Jain A, Soni V, Gupta Y, Jain SK. Cross linked guar gum microsphere: A viable approach for improved delivery of anticancer drug for the treatment of colorectal cancer. AAPS Pharm Sci Tech 2006;7:1-9.

12. Lorenzo-Lamosa, ML, Remuna-Lopez, Vilajato JL, Alonso MJ, Design of microencapsulated chitosan microspheres for colonic drug delivery J Control Release 1998;5:109-118.

13. Krishnamachari M, Malarski Z, Mrozinski J, Wajcht J,Zborucki, Z. Influence of solvent effect on polymorphism of 4-hydroxy-2methyl-N-2-pyridyl-2H-1,2-benzothiazine-3carboxamide-1,1-dioxide (piroxicam). J Crystallography Spectroscopy Res 2007; 21:519-522.

14. Chaurasia N, Moghadam SH, Atyabi F, Dinarvand R. Preparation and characterization of estradiol valerate microspheres using biodegradable polymers. Iranian J Pharm Sci 2004:2:3-10.

15. Martin A, Bustamante P, Chun A. Micromeritics in Physical Pharmacy- Physical Chemical Principles in Pharmaceutical Science 4th ed., New York, Lippincott Williams and Wilkins, 2002.

16. Vyas SP, Khar RK. Controlled Drug Delivery, New Delhi, Vallabh Prakashan, 2005.

17. Rowe RC, Sheskey PJ, Owen SC. Handbook of Pharmaceutical Excipient (5th ed). London, Pharmaceutical Press, 2006.

18. Anande NM, Jain SK, Jain NK. Con-A conjugated mucoadhesive microspheres for the colonic delivery of diloxanide furoate. Int J Pharm 2008;359:182-9.

19. Vats A, Pathak K. Tabletted guar gum microspheres of piroxicam for targeted adjuvant therapy for colonic adenocarcinomas. Therapeutic Deliv 2012;3:1281-95.

20. Wu J, Wei L, Wang Y, Su Z, Ma G. Preparation of uniform-sized $\mathrm{pH}$-sensitive quaternized chitosan microspheres by combining membrane emulsification technique and thermal-gelation method. Colloids Surf B Biointerfaces 2008;63:164-75.

21. Rahman Z, Kohli K, Khar RK, Ali M, Charoo NM. Characterization of 5-fluorouracil microspheres for colonic delivery. AAPS Pharm Sci Tech 2006;7:113-21.

22. Babu VR, Sairam M, Hosamani KM, Aminabhvi TM. Preparation of sodium alginate-methylcellulose blend microspheres for controlled release of nifedipine. Carbohydrate Polymer 2007; 69:241-50.

23. Yadav AV, Mote HH. Development of biodegradable starch microspheres for intranasal delivery. Indian J Pharm Sci 2008;70:170-4.

24. Mishra S, Patel N, Kumar M, Pathak K. Crosslinked mucoadhesive microspheres based on anionic heteropolysaccharide for nasal delivery of felodipine: optimization and in vitro evaluation, Drug Deliv Letters 2013;3:136-48.

25. Chaio YB, Cheng F, Choi H, Kim KK. Uniform chitosan microspheres for potential application to colon-specific drug delivery. Macromolecule Biosci 2008;8:1173-81.

26. Florey K. Analytical Profiles of Drug Substances, Academic press, London, 2005;15, pp. 509-20.

27. Mudgil D, Barak S, Khatkar BS. X-ray diffraction, IR spectroscopy and thermal characterization of partially hydrolyzed guar gum. Int J Biol Macromo 2012;50:1035-9.

28. Srivastava R, Kumar D, Pathak K. Colonic luminal surface retention of meloxicam microsponges delivered by erosion based colon targeted matrix tablet. Int $\mathbf{J}$ Pharm 2012;427:153-62.

29. Sharma P, Pathak K. Inulin based tablet in capsule device for variable multiple delivery of aceclofenac: optimization and in vivo roentgenography. AAPS Pharm Sci Tech 2013;14:736-47. 